\title{
KEANEKARAGAMAN HAMA DAN MUSUH ALAMI PADA TANAMAN PALA (Myristica fragrans HOUTT.) DI ACEH SELATAN
}

\author{
Sumeinika Fitria Lizmah ${ }^{1}$, Agustinur $^{1}$, Muhammad Sarong ${ }^{3}$ \\ ${ }^{1}$ Dosen Program Studi Agroteknologi, Fakultas Pertanian, Universitas Teuku Umar \\ ${ }^{2}$ Mahasiswa Program Studi Agroteknologi, Fakultas Pertanian, Universitas Teuku Umar \\ Email: sumeinika@gmail.com
}

\begin{abstract}
The diversity of insects, both pests and natural enemies in each place differently is influenced by environmental factors and technical culture of cultivation. This study aims to determine the diversity of pests and natural enemies in nutmeg plants in South Aceh. Insect sampling was carried out at nutmeg plantations in South Aceh, followed by identification in the Faculty of Agriculture laboratory, Teuku Umar University. Methods of data collection using purposive sampling, using light traps, pit fall traps, yellow traps. The Parameters of this study are number of individuals, families, and insect diversity obtained. The results showed that the abundance of pests and natural enemies in Meukek was higher compared to Samadua. The ShannonWiener index shows a variety of pests in Meukek high $\left(H^{\prime}=3,029\right)$ and moderate in Samadua $\left(H^{\prime}=2,788\right)$. While the diversity of natural enemies in both Meukek and Samadua is relatively low, namely $H^{\prime}=1.230$ and $H^{\prime}=1.049$. Planting patterns and crop management affect the abundance and diversity of both pests and natural enemies in both locations. Plantations in Meukek tend to be heterogeneous which are planted with a variety of plantation crops (polyculture) while nutmeg plants in the same two are relatively homogeneous (monoculture nutmeg).
\end{abstract}

Keywords: diversity, pests, parasitoids, predators, nutmeg

\section{PENDAHULUAN}

\section{Latar Belakang}

Pala tergolong dalam famili Myristicaceae yang banyak digunakan masyarakat Indonesia sebagai rempah, obat-obatan (Hariana, 2009). Selain itu, daging buah pala dapat dimanfaatkan untuk diolah menjadi manisan pala, asinan pala, dodol pala, selai pala dan sirup pala. Tanaman pala (Myristica fragrans Houtt) merupakan tanaman purba endemik Indonesia yang berasal dari kepulauan Banda, Provinsi Maluku (Wakim et al., 2014).

Kabupaten Aceh Selatan dikenal sebagai sentra produksi pala di kawasan Aceh dan Provinsi Aceh sendiri merupakan salah satu penghasil pala ketiga terbanyak nasional setelah Maluku Utara dan Maluku (Direktorat Jenderal Perkebunan, 2011). Berdasarkan data statistik, luas areal tanaman pala di Indonesia sebesar 134.079 ha dengan produksi 25.321 ton (Direktorat Jenderal Perkebunan, 2013). Menurut Dinas Kehutanan dan Perkebunan Aceh dalam Idawanni (2015), luas perkebunan pala Aceh Selatan mengalami peningkatan dari 11.245 Ha menjadi 14.183 Ha (Tahun 1994-2011), namun produktivitas pala menurun hampir setengahnya yaitu dari 8.647 ton ke 4.650 ton.

Penurunan produksi pala di Aceh Selatan disebabkan beberapa faktor, diantaranya banyak tanaman berumur tua, kurangnya pemeliharaan, serta serangan hama dan penyakit. Serangan hama dan penyakit pada tanaman pala menyebabkan banyak tanaman yang mati. Menurut laporan Mardiningsih et al. (2015), serangan hama pada tanaman pala dimulai dari fase pembibitan hingga pasca panen. Trips Liothrips sp. nr. floridensis (Thysanoptera: Phlaeothripidae), kutu tempurung Drepanococcus sp. 
(Coccidae), dan kutu perisai (Diaspididae) adalah jenis hama yang menyerang pada saat pembibitan.

Kumbang penggerak batang (Batocera hercules) dan penggerek ranting Xyleborus sp. telah dilaporkan menyerang batang tanaman pala berbagai stadia umur di berbagai daerah (Badan Litbang Pertanian, 2011; Umasangaji et al., 2012; Vitali, 2015). Selain di Indonesia, Batocera sp. juga ditemukan di Philipina, Sri Lanka dan Papua New Guine (Mercer 1993 dalam Defoliart 1995). Kumbang Araecerus fasciculatus (Fabricus), Tribolius confusum (Jack du Val), hama bubuk biji Poecilips myristiceae merupakan hama pascapanen yang dilaporkan menyerang biji pala (Direktorat Pascapanen dan Pembinaan Usaha, 2012).

Pengendalian hama pada tanaman perkebunan dapat dilakukan dengan penggunaan musuh alami baik berupa parasitoid maupun predator. Beberapa jenis parasitoid lainnya yang sering dijumpai pada areal perkebunan yaitu parasitoid famili Brachonidae, Ichneumonidae, dan Torymidae. Pemanfaatan jenis serangga predator seperti kepik pembunuh (famili Reduviidae) dan kumbang tempurung (Famili Coccinellidae) juga sering kali dilakukan pada tanaman-tanaman perkebunan (Ambrose, 1999).

Menurut Badan Litbang

Pertanian, (2011), penggerek batang atau ranting dapat dikendalikan oleh jamur Beauveria bassiana, sementara Harni et al. (2011) menyatakan penggerek batang dapat juga dikendalikan menggunakan parasitoid lalat Tachinidae. Di India pengendalian Liothrips karnyi menggunakan kepik predator Montandoniola indica Yamada sp. nov. (Hemiptera: Heteroptera: Anthocoridae) (Yamada et al., 2011).

Berdasarkan pernyataan diatas, penggunaan musuh alami penting untuk dilakukan, untuk itu diperlukan data awal mengenai jenis dan kelimpahannya di habitat tanaman pala. Oleh karena itu penelitian keanekaragaman hama pada perkebunan pala di Aceh Selatan ini perlu untuk dilakukan sehingga dapat menghasilkan informasi mengenai keanekaragaman hama dan musuh alami yang nantinya dapat dijadikan dasar pertimbangan dalam pengendalian hama, terutama pengendalian hama secara biologis.

\section{Tujuan Penelitian}

Penelitian ini bertujuan unuk mengetahui keanekaragaman hama dan musuh alami pada perkebunan pala di Aceh Selatan.

\section{METODE PENELITIAN}

Tempat dan Waktu Penelitian

Pengambilan sampel serangga dilakukan di perkebunan pala milik masyarakat di Aceh Selatan, yaitu di Kecamatan Meukek dan Kecamatan Samadua. Identifikasi serangga yang diperoleh dilakukan di Laboratorium Fakultas Pertanian Universitas Teuku Umar, Meulaboh-Aceh Barat dan Laboratorium Hama dan Penyakit Balai Pengawasan Hama dan Penyakit Tanaman Pangan dan Hortikultura, Pulo Ie, Kabupaten Nagan Raya. Pelaksanaan penelitian ini dari bulan Mei sampai Oktober 2018.

Pelaksanaan Penelitian

Penentuan Lokasi Penelitian

Lokasi penelitian dipilih berdasarkan hasil survey lokasi yang dilakukan sebelum memulai penelitian. Kriteria lokasi yang dipilih adalah perkebunan pala milik masyarakat dengan luasan lahan perkebunan pala yaitu $\pm 100 \mathrm{~m}^{2}$. Berdasarkan hasil survey, diperoleh dua lokasi yang sesuai yaitu yang berada di Kecamatan Meukek dan Kecamatan Samadua.

Pengambilan Contoh Serangga

Perangkap cahaya (light trap)

Perangkap ini dipasang sebanyak 1 unit untuk masing-masing lokasi setiap 
hari selama 3 hari berturut-turut. Pemasangan perangkap dilakukan pada pukul 18.00. Serangga yang tertampung di dalam botol penampung diambil keesokan harinya pada pukul 07.00 WIB.

\section{Perangkap jebak (pit fall trap)}

Perangkap jebak berupa gelas plastik berukuran $250 \mathrm{ml}$ yang kemudian dimasukkan ke dalam lubang galian sampai ke bibir gelas. Selanjutnya gelas diisi 3/4 bagian dengan larutan campuran deterjen, air, dan alkohol dengan perbandingan 1:2:1. Perangkap jebak dipasang 5 unit di setiap lokasi dan diulang tiga hari bertutur-turut, waktu pemasangannya dari pukul 08.00 WIB sampai 17.00 WIB. Serangga yang terkumpulkan dipisahkan dari serasah dengan menggunakan saringan, kemudian dimasukkan ke dalam botol penampung dengan menggunakan pinset dan kuas kecil.

Perangkap nampan kuning (yellow pan trap)

Perangkap nampan kuning menggunakan sebuah nampan atau baskom berwarna kuning untuk menarik serangga. Perangkap ini dipasang sebanyak 5 unit secara acak di setiap lokasi penelitian. Perangkap dipasang selama 3 hari dari pukul 08.00-17.00 WIB. Hasil serangga yang diperoleh disaring dan dimasukkan ke botol koleksi yang telah berisi alkohol $70 \%$ sebagai pengawet, untuk kemudian dibawa ke laboratorium untuk diidentifikasi

Parameter Penelitian
Parameter yang diamati adalah
jumlah individu, keanekaragaman serangga yang diperoleh. Keanekaragaman dihitung berdasarkan Indeks Keanekaragaman Shannon-Wiener (H').

Dimana:

$$
H^{\prime}=-\sum \text { pi LN pi }
$$

$\mathrm{H}^{\prime}=$ indeks keanekaragaman ShannonWiener

$\mathrm{pi}=\mathrm{ni} / \mathrm{N}$

$\mathrm{ni}=$ jumlah individu yang ditemukan

$\mathrm{N}=$ jumlah total individu yang ditemukan

$\mathrm{LN}=$ logaritme natural

Selain parameter diatas, dilakukan

juga pengamatan pada luas serangan penggerek batang pada tanaman pala. Pengamatan ini dilakukan pada 20 tanaman sampel pada masing-masing lokasi. Diamati gejala kerusakan yang terlihat kemudian dihitung dengan rumus sebagai berikut:

Dimana:

$$
\mathrm{L}=\frac{\mathrm{a}}{\mathrm{b}} \times 100 \%
$$

$\mathrm{L}=$ Luas serangan $(\%)$

$\mathrm{a}=$ Jumlah Tanaman yang terserang

$\mathrm{b}=$ total tanaman yang diamati

\section{HASIL PENELITIAN}

Berdasarkan data yang telah diperoleh, kelimpahan dan komposisi serangga hama yang ditemukan pada kedua lokasi penelitian terdiri dari 14 Ordo, 70 Famili dan 490 individu. Keanekaragaman dan kelimpahan serangga pada perkebunan pala di Kecamatan Meukek lebih tinggi dibandingkan dengan yang berada di Meukek (Tabel 1).

Tabel 1. Keanekaragaman hama pada tanaman pala di Aceh Selatan

\begin{tabular}{lcccc}
\hline \multirow{2}{*}{ Parameter } & \multicolumn{2}{c}{ Meukek } & \multicolumn{2}{c}{ Samadua } \\
\cline { 2 - 5 } & Hama & Musuh Alami & Hama & Musuh Alami \\
\hline Individu & 251 & 135 & 61 & 36 \\
Famili & 41 & 13 & 22 & 5 \\
H' & 3.029 & 1.230 & 2.788 & 1.049 \\
\hline
\end{tabular}

Kelimpahan spesies serangga pada tanaman pala di Kecamatan Meukek lebih tinggi dari pada di kecamatan Sama dua. Adanya perbedaan topografi dan keragaman vegetasi diduga menjadi faktor penentu nilai keanekaragaman di kedua lokasi tersebut. Perkebunan pala yang berada di Kecamatan Meukek berada di 
pegunungan dan memiliki sumber air tawar berupa sungai. Jenis tanaman yang berada di sekitar tanaman pala pun beragam, seperti kenari, manga, durian, kakao, nilam, dan cengkeh. Sementara itu lokasi perkebunan pala di Kecamatan Samadua berada berbatasan dengan pantai dan pemukiman masyarakat, serta hanya ditanami dengan tanaman pala saja.

Kondisi tersebut dikarenakan ketersediaan sumber daya seperti makanan yang juga melimpah. Keanekaragaman serangga pada suatu habitat berkaitan dengan melimpahnya sumberdaya tanaman, terutama serbuk sari dan nektar (Fajarwati et al., 2009). Menurut Lizmah (2015), lanskap pertanian yang kompleks dengan keragaman vegetasi tinggi, sangat mendukung keberlangsungan populasi akibat makanan yang selalu tersedia.

Berdasarkan indeks ShannonWiener (Tabel 1.), keanekaragaman hama di Meukek tergolong tinggi (H'>3), akan tetapi keanekaragaman musuh alami di kedua lokasi tergolong sedang $\left(1>\mathrm{H}^{\prime}<3\right)$. Keadaaan ini diduga berkaitan dengan pengaruh dari kondisi lingkungan seperti cuaca, ketersediaan makanan, dan kepadatan populasi dari masing-masing serangga. Selain itu, pola tanam dan pengelolaan tanaman diduga mempengaruhi keanekaragaman dan kelimpahan musuh alami di kedua lokasi. Perkebunan pala di Meukek cenderung heterogen yang ditanami berbagai macam tanaman perkebunan (polikultur) sementara tanaman pala di Samadua relatif homogen (monokultur pala). Perkebunan Pala di Meukek juga ditanami tanaman lain seperti kako, durian, cengkeh, dan kemiri. Keadaan tersebut menyebabkan serangga baik hama, parasitoid, maupun predator lebih banyak. Menurut Herlinda (2000) dimana keanekaragaman spesies serangga hama di suatu habitat dipengaruhi oleh struktur vegetasi tumbuhan yang kompleks (polikultur), semakin kompleks suatu habitat maka kekayaan spesies serangga hama akan semakin tinggi.

Kondisi tersebut juga mendukung tersedianya sumber daya pakan dan tempat tinggal bagi serangga-serangga tersebut. Keadaan ini berbeda dengan hasil pada lokasi Samadua dimana baik nilai kelimpahan maupun keanekaragaman serangganya lebih rendah. Menurut Lizmah (2015), vegetasi yang beragam di sekitar areal pertanian dapat meningkatkan kelimpahan spesies dan famili serangga. Lanskap heterogen cenderung memiliki keanekaragaman musuh alami lebih tinggi dibandingkan dengan lanskap sederhana (Purtauf et al., 2005).

Tabel 2. Gejala serangan hama pada tanaman pala

\begin{tabular}{lccc}
\hline \multicolumn{1}{c}{ Lokasi } & Tanaman terserang & $\begin{array}{c}\text { Tanaman yang } \\
\text { diamati }\end{array}$ & Luas serangan (\%) \\
\hline Meukek & 13 & 20 & 65 \\
Samadua & 4 & 20 & 20 \\
\hline
\end{tabular}

Hasil pengamatan gejala serangan penggerek batang pala (Batocera hercules) menunjukkan bahwa di lokasi Meukek terjadi gejala serangan sekitr $65 \%$ yang artinya perkembangan penggerek batang di lokasi ini sangat tinggi dibandingkan dengan lokasi Samadua (Tabel 2). Selain kondisi lingkungan dan vegetasi, kebersihan lahan dan perawatan tanaman juga dapat memicu tingginya serangan pada suatu lahan pertanian atau perkebunan. Menurut Pracaya (2008), perawatan kebun dan sekitarnya akan meniadakan tempat hama untuk bertelur dan bersembunyi.

Pohon yang terserang hama Batocera hercules dapat dikenali dengan adanya lubang-lubang gerekan sebesar 2,5$3 \mathrm{~cm}$, kumbang ini banyak ditemukan di daerah Aceh dengan intensitas kerusakan sebesar $15-40 \%$. Batocera hercules juga telah dilaporkan menyerang pala di daerah 
Sulawesi Utara dengan intensitas serangan $17-24 \%$ dan dapat menurunkan produksi pala sampai 24\% (Badan Litbang Pertanian, 2011). Hasil penelitian Umangsaji et al. (2012) menunjukkan bahwa tingkat serangan hama Batocera hercules pada areal pertanaman pala Kecamatan Wakate, Pulau Watubela, Maluku, sebesar 19,19\% dengan jumlah lubang gerekan 2,08. Besar serangan pada tanaman pala jenis Banda, Onin, dan silang masing-masing sebesar $23,01 \%, 30,28 \%$ dan 4,28 \%. Besarnya tingkat serangan ditentukan oleh faktor kultur teknis dan faktor iklim.

Umumnya perkebunan pala di Aceh Selatan merupakan perkebunan milik masyarakat yang dikelola secara tradisional sehingga pemeliharaan dan pengelolaannya kurang dilakukan dengan intensif, termasuk penanganan pascapanen. Kasus serangan serangga hama di tanaman pala banyak ditemukan di Aceh Selatan dan Aceh Barat Daya (Mardiningsih et al. 2015). Hama tanaman pala mampu menyerang sekitar $30 \%$ tanaman pala sehingga produksi pala mengalami penurunan yang signifikan (Hanum, 2002). Kerusakan pala akibat serangan hama mengurangi tanaman produktif hingga $31,3 \%$ dan menurunkan produksi hingga $24,7 \%$ dari produksi praserangan hama (Dwiartama, 2008).

Beberapa famili musuh alami yang ditemukan pada tanaman pala di kedua tercantum pada Tabel 3 berikut:

Tabel 3. Famili musuh alami yang ditemukan di kedua lokasi

\begin{tabular}{llll}
\hline & Meukek & \multicolumn{2}{c}{ Samadua } \\
\hline Parasitoid & Predator & Parasitoid & Predator \\
\hline Aphelinidae & Formicidae & Braconidae & Formicidae \\
Cynipidae & Specidae & Bethylidae & \\
Drynidae & Vespidae & Diapriidae & \\
Encyrtidae & & Scelionidae & \\
Eurytomidae & & & \\
Evaniidae & & & \\
Ichneumonidae & & & \\
Scelionidae & & & \\
Torymidae & & & \\
\hline
\end{tabular}

Kelimpahan musuh alami di kedua lokasi baik parasitoid dan predator cenderung lebih sedikit dibandingkan dengan jumlah hama. Akan tetapi keragaman musuh alami tersebut berkorelasi dengan jumlah hama yang ditemukan, dimana kelimpahan dan jenis hama di Meukek juga lebih tinggi daripada di Samadua. Predator yang ditemukan didominasi oleh famili Formicidae, terutama dari subgenus Myrmicinae dan Dolichoderus sp. (Gambar 1.). Sementara parasitoid yang ditemukan pada perkebunan pala adalah famili Diapriidae, Drynidae, Scelionidae, dan Torymidae (Gambar 2).

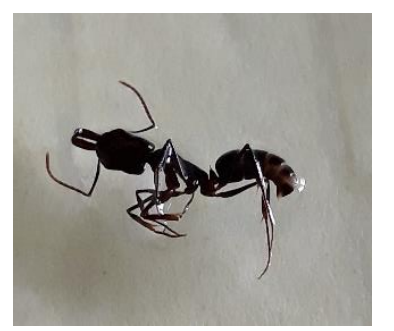

Gambar 1. Predator Dolichoderus sp. 


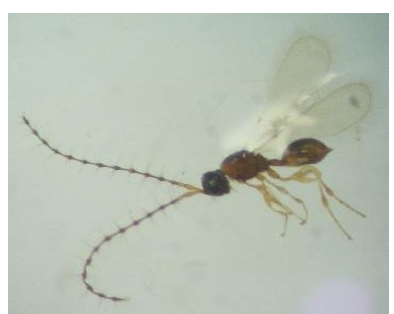

a

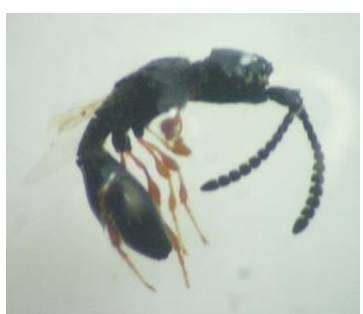

b

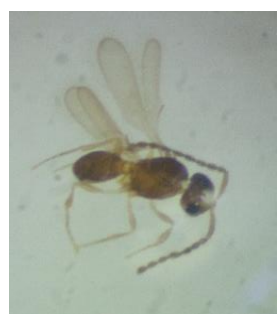

$\mathrm{c}$

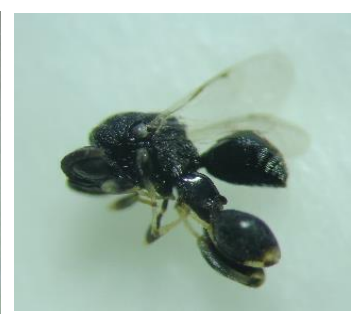

d

Gambar 1. Beberapa parasitoid yang ditemukan pada perkebunan pala (a. Diapriidae, b. Drynidae, c. Scelionidae, d. Torymidae)

\section{KESIMPULAN}

Adapun kesimpulan dari penelitian ini adalah keanekaragaman hama dan musuh alami di Kecamatan Meukek lebih tinggi dibandingkan dengan kecamatan Samadua. Nilai keanekaragaman pada masing-masing habitat pertanian dan perkebunan dipengaruhi oleh keragaman vegetasi, pengelolaan kebun, dan habitat di sekitar.

\section{DAFTAR PUSTAKA}

[CSIRO] Commonwealth Scientific and Industrial Research Organisation. 2001. The insect of Australia. Australia: Melbourne University Press.

Agoes A. 2010. Tanaman Obat Indonesia. Salemba Medika. Jakarta. 110 hlm.

Altieri MA, Nicholls CI. 2004. Biodiversity and Pest Management in Agroecosystems. Binghamton (US): Imprint Haworth Pr.

Badan Litbang Pertanian. 2011. Pengendalian Terpadu Hama dan Penyakit Utama Pala. Agroinovasi Edisi 23 Pebruari - 1 Maret 2011 No.3394 Tahun XLI.

Clarke KR. 1993. Non-parametric multivariate analyses of change in community structure. Australian Journal of Ecology. 18: 117-143.

Defoliart, G.R. 1995. Edible insects as Minilivestock. Biodiversity and Conservatio 4: 306-32I.
Direktorat Jenderal Perkebunan, Direktorat Pascapanen dan Pembinaan Usaha. 2012. Pedoman Teknis Penanganan Pascapanen Pala. Kementerian Pertanian. Jakarta.

Dwiartama A. 2008. Evaluasi Dan Penyusunan Strategi Pengelolaan Perkebunan Pala Rakyat Di Desa Paya Teuk, Kecamatan Pasieraja, Kabupaten Aceh Selatan. Tesis. ITB, Bandung.

Fajarwati MR. 2009. Keanekaragaman serangga pada lahan organik. Jurnal Entomologi Indonesia. Vol. 6 No. 2.

Hanum CS. 2002. Tanaman pala di Kabupaten Aceh Selatan: sang primadona yang digerogoti penyakit. Harian Kompas, Senin 5 Agustus 2002.

Harian A. 2009. Tumbuhan Obat dan Khasiatnya. Penebar Swadaya, Jakarta.

Harper JL, Hawksworth DL. 1995. Bodiversity: Measurement and Estimation. Hawksworth DL, editor. London (UK): Chapman \& Hall.

Herlinda. 2000. Analisa KOmunitas arthropoda penghuni lanskap di daerah cianjur. [skripsi]. Bogor (ID): Institut Pertanian Bogor.

Idawanni. 2015. Pengembangan Usaha Pengolahan Komoditi Pala Aceh. http://nad.litbang.pertanian.go.id/i nd/index.php/info-teknologi/775pengembangan- usaha-komoditipala-aceh. Diakses tanggal 13 Juni 2017. 
LaSalle J, Gauld ID. 1993. Hymenoptera and Biodiversity. LaSalle $\mathrm{J}$, Gauld ID, editor. London (UK): C.A.B. International.

Leather SR. 2008. Insect Sampling in Forest Ecosystems. West Sussex (UK): Wiley- Blackwell: J Wiley.

Lizmah FL. 2015. Pengaruh struktur lanskap terhadap keanekaragaman terhadap keanekaragaman Hymenoptera parasitika pad alaham mentimun. [tesis]. Bogor (ID): Institut Pertanian Bogor.

Mardiningsih TL, Balfas R, Wahyono TE. 2015. Hama potensial pada perbenihan pala (Myristica fragrans Houtt). Prosiding Seminar Perbenihan Tanaman Rempah dan Obat

Nurdjannah N. 2007. Teknologi Pengolahan Pala. Badan Penelitian dan Pengembangan Pertanian, Balai Besar Penelitian dan Pengembangan Pascapanen Pertanian. Peraturan Menteri Pertanian. Nomor 53/Permentan/OT.140/9/2012. Pedoman Penanganan Pascapanen Pala. Peraturan Menteri Pertanian. Jakarta.

Rismunandar. 1992. Budidaya dan Tataniaga Pala. PT. Penebar Swadaya. Jakarta.

Scherber C, Lavandero B, Meyer KM, Perovic D, Visser U, Wiegand K, Tscharntke T. 2012. Biodiversity and Insect Pests: Key Issues for Sustainable Management. Gurr. GM, Wratten SD, Snyder WE, Read DMY, editor. West Sussex (UK): Wiley- Blackwell: J Wiley.
Susanto H. 2003. Budidaya Pala, Komoditas Ekspor. Kanisius, Yogyakarta.

Umasangaji A, Patty J.A, Rumakamar A.A. 2012. Kerusakan Tanaman Pala akibat Serangan Hama Penggerek Batang (Batocera hercules). Agrologia. Vol. 1, No. 2, Hal. 163-169

Wakim M, Dalijama Z.A, Eirumkuy E, Tupan J. 2014. Katalog Pameran Budayya dan Sejarah Daerah Maluku: Identitas ke-Maluku-an. Balai Pelestarian Nilai Budaya Ambon, Ambon.

Yamada K, Bindu K, Nasreem A, and Nasser M. 2011. A New Flower Bug of the Genus Montandoniola (Hemiptera: Heteroptera: Anthocoridae), a Predator of Gall- forming Thrips on Black Pepper in Southern India. Acta Entomologica Musei Nationalis Pragae 51(1): 1-10. 